International Journal of Engineering \& Technology, $7(1.1)(2018)$ 679-684
SPC
International Journal of Engineering \& Technology
Website www.sciencepubco.com/index.php/IJET
Research paper

\title{
Plan and analysis of synchronous buck converter for UPS application
}

\author{
Jadapalli. Sreedhar $1 *$, B. Basavaraja ${ }^{2}$ \\ ${ }^{1}$ Research Scholar, Eee Dept., Gitam University, Hyderabad \\ ${ }^{2}$ Professor and Head, University BDT College of Engineering \\ *Corresponding author E-mail: sreedharmtech@gmail.com
}

\begin{abstract}
DC-DC converters occupies very significant role in the field of industries or daily life applications. To charge batteries of low voltage connected to uninterrupted power supply (UPS), DC-DC converters are needed. Batteries requires low voltage and the available voltage at the source is to be step-down to the required level of voltage at the point of utility (PoU). While designing DC-DC converters, efficiency and simplicity of the circuit is very much important. Simply for the UPS applications, Buck converter can deliver the voltage at required level which is very simple in operation but the increased losses in diode can be addresses by using a synchronous Buck converter. By using synchronous Buck converter, the diode conduction losses in Buck converter can be minimized, thus improving the efficiency of the converter. In this paper, Synchronous Buck converter is used to charge the batteries of UPS. In this paper Design, modeling of synchronous Buck converter for UPS application was done and its results were obtained by using Matlab/Simulink. A hardware prototype was also developed and the hardware results were also shown.
\end{abstract}

Keywords: Uninterrupted Power Supply (UPS); DC-DC Converter; Point of Utility (PoU); Buck; Synchronous Buck; Conduction Losses.

\section{Introduction}

Many DC-DC converters are available either to increase or to decrease the voltage from source to the point of utility. Choosing best suitable converter depending on the application is very crucial. Converters selected should have high operating efficiency, low cost, simple in construction. Many converters employs low switches to reduce the losses [1-2]. Design of any converter depends on duty cycle [3]. Buck converter is very simple in construction and can effectively decrease the voltage level available at source to the voltage level which is required at the point of usage [4]. The main concept which should be kept in mind while designing a converter is the device reverse voltage, forward voltage drop and forward current. Where the rated reverse voltage should be at least $2 \mathrm{~V}$ higher than the peak voltage at switch node and higher efficiency can be achieved when we have less voltage drop. The peak current rating of the device should be higher than the maximum output current through switch plus one-half the peak inductor current.

Buck converter effectively step-down the level of voltage but the Buck circuit consists of diode. When the main switch is on, the diode does not conduct. But when the diode starts conduction, the losses that occur in diode, called conduction losses increases when the ON time of diode increase. Due to these conduction losses in diode, the efficiency of the converter might decrease. To increase the efficiency reducing the conduction losses, this paper proposes Synchronous Buck converter where the diode in the Buck converter is replaced with another switch in Synchronous Buck converter. The two switches in Synchronous converter are synchronously operated such that no overlap takes place in their ON time. The introduction of MOSFET over a diode typically reduces the drop from $0.5 \mathrm{~V}$ to $1 \mathrm{~V}$ of diode to a value of $0.3 \mathrm{~V}$ or less. This in- turn increases the efficiency of the converter by $5 \%$ or high [5]. Many switching techniques were discussed but very few were implemented for high power applications [6-9]. ZVS switching technique, a method of soft switching has given better performance [10-12].

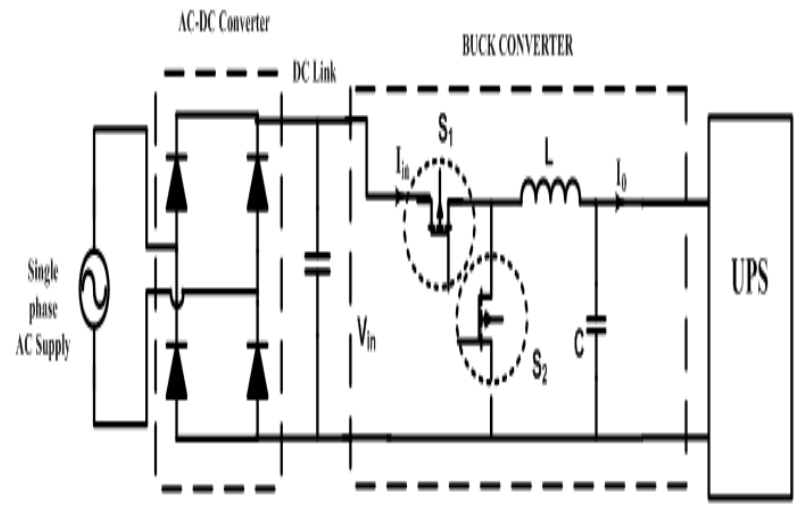

Fig. 1: Basic Diagram of Synchronous Buck Converter for UPS Application.

The basic diagram of such Synchronous Buck converter for UPS load application is shown in figure 1 . The available AC source is first to be converted to DC with a simple diode bridge rectifier. The rectified output is fed to DC-DC converter through a DC link voltage. This DC link voltage maintains constant DC voltage at the input of synchronous Buck converter. Synchronous buck converter circuit does not vary much but only the diode in normal buck converter is replaced with a switch generally MOSFET. This synchronous buck converter step-down the input voltage and 
charges the batteries to drive UPS. This paper discusses the application of Synchronous Buck converter to charge batteries of UPS with both open loop operation and closed loop operation. Results were obtained using Matlab/Simulink. The simulink results pertaining to normal buck converter with open loop and closed loop operations were also discussed.

\section{Operation of converter}

Both buck converter and synchronous buck converter is similar in operation but with diode in buck converter will be replaced with a switch in synchronous Buck converter.

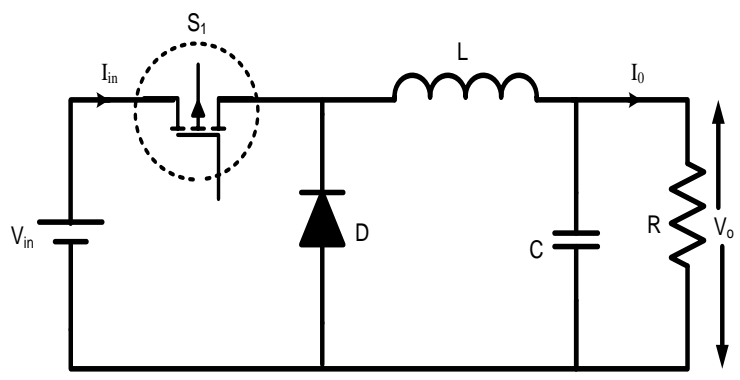

Fig. 2: Basic Circuit Diagram of Buck Converter.

A simple schematic circuit of Buck converter is shown in figure 2 and synchronous buck converter is shown in figure 3 . The operation of buck converter mainly depends on the charging of inductor through switch and discharging of inductor through diode. While inductor is been discharged through diode, diode conducts over a period of time. Diode will have high conduction losses and this losses makes efficiency low. So due to the diode conduction, efficiency of buck converter is low. This problem can be eliminated if we can replace this diode with a switch having less conduction losses. This replacement of diode with a switch makes synchronous buck converter.

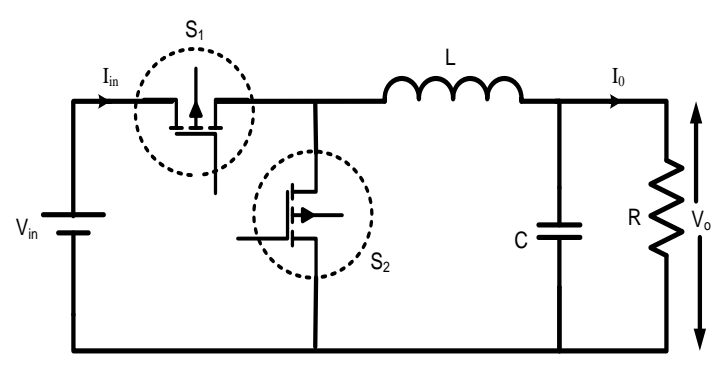

Fig. 3: Basic Diagram of Synchronous Buck Converter.

Suppose, if the duty cycle is $25 \%$, means the main switch conducts for $25 \%$ of the cycle time when compared to the $75 \%$ conduction time of switch S2 over a cycle. Since the conduction time of the secondary switch S2 is high when compared to S1, there will be losses present across switch $\mathrm{S} 2$ and this is the main criteria why we are going for synchronous buck converter. In a simple buck converter as shown in figure 3, the diode conduction losses are high. Diode forward conduction losses are high when compares to MOSFET. The introduction of MOSFET over a diode typically reduces the drop from $0.5 \mathrm{~V}$ to $1 \mathrm{~V}$ of diode to a value of $0.3 \mathrm{~V}$ or less. This in-turn increases the efficiency of the converter by $5 \%$ or high.

\section{Design of converter}

$V_{\text {in }}$ is the source voltage and $I_{s}$ is the source current. $S_{1}$ is the main switch, $\mathrm{D}$ is diode, $\mathrm{L}$ is inductor and $\mathrm{C}$ is capacitor. $\mathrm{R}$ is the load connected and $\mathrm{V}_{0}$ is the output voltage.

When $\mathrm{S}_{1}$ is $\mathrm{ON}$ and diode OFF

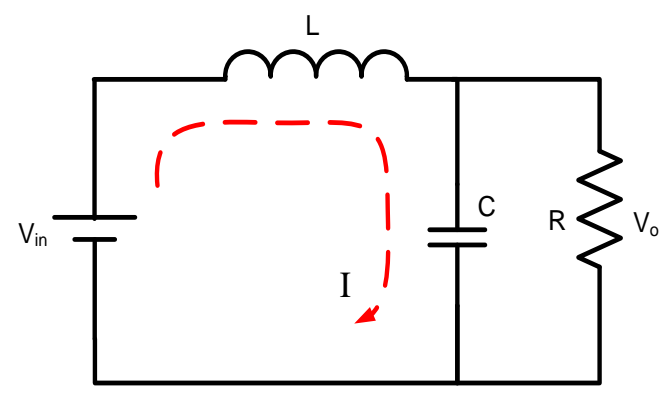

$\mathrm{V}_{\text {in }}-\mathrm{V}_{0}=\mathrm{L} \frac{\mathrm{dI}}{\mathrm{dt}}$

Assume $\mathrm{dI}=\mathrm{I}_{2}-\mathrm{I}_{1}$

$\mathrm{dt}=\mathrm{t}_{1}$

$\mathrm{V}_{\text {in }}-\mathrm{V}_{0}=\mathrm{L} \frac{\Delta \mathrm{I}}{\mathrm{t}_{1}}$

$\mathrm{t}_{1}=\frac{\Delta \mathrm{I} \times \mathrm{L}}{\left(\mathrm{V}_{\mathrm{in}}-\mathrm{V}_{0}\right)}$

When switch is OFF and

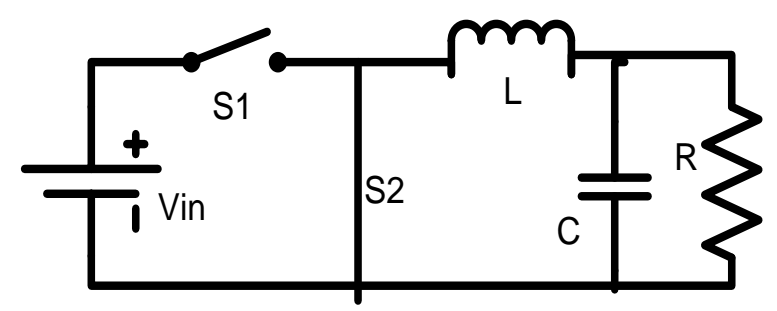

$-\mathrm{V}_{0}=-\mathrm{L} \frac{\Delta \mathrm{I}}{\mathrm{t}_{2}}$

$\mathrm{t}_{2}=\frac{\mathrm{L} \Delta \mathrm{I}}{\mathrm{V}_{0}}$

Total switching period $\mathrm{T}$

$\mathrm{T}=\frac{1}{\mathrm{f}}=\mathrm{t}_{1}+\mathrm{t}_{2}=\frac{\Delta \mathrm{ILV} \mathrm{V}_{\text {in }}}{\mathrm{V}_{0}\left(\mathrm{~V}_{\mathrm{in}}-\mathrm{V}_{0}\right)}$

This simplifies to

$\Delta \mathrm{I}=\frac{\mathrm{V}_{\text {in }} \mathrm{D}(1-\mathrm{D})}{\mathrm{f}_{\mathrm{L}}}$

The average capacitor current is

$\mathrm{I}_{\mathrm{c}}=\frac{\Delta \mathrm{I}}{4}$

$\mathrm{V}_{\mathrm{c}}=\frac{1}{\mathrm{C}} \int \mathrm{i}_{\mathrm{c}} \mathrm{dt}$

Which gives

$\Delta V_{c}=\frac{\Delta I}{8 f c}$

Substitute $\Delta \mathrm{I}$

$\Delta \mathrm{V}_{\mathrm{c}}=\frac{\mathrm{V}_{\mathrm{in}} \mathrm{D}(1-\mathrm{D})}{8 \mathrm{LCf} \mathrm{f}^{2}}$

$\mathrm{V}_{\text {in }}=320 \mathrm{~V}$ d.c, $\mathrm{V}_{0}=144 \mathrm{~V}$

$\mathrm{P}_{0}=3.6 \mathrm{~kW}, \mathrm{I}_{0}=25 \mathrm{~A}$

$\mathrm{f}=50 \mathrm{~Hz}, \mathrm{D}=0.5$ 
Assume $\Delta \mathrm{I}, \Delta \mathrm{V}_{\mathrm{c}}$ as $5 \%$ \& $2 \%$ ripples

The value of ' $\mathrm{L}$ ' is calculated as $\mathrm{I}_{0}=\mathrm{I}_{\mathrm{L}}=25$,

$\Delta \mathrm{I}=\frac{5 \times 25}{100}=1.25 \mathrm{~A}$

$\mathrm{L}=\frac{320 \times 0.45 \times(1-0.45)}{50 \times 10^{3} \times 1.25}$

$\mathrm{L}=1.26 \mathrm{mH}$

The Value of ' $\mathrm{C}$ ' is calculated as

$\Delta \mathrm{V}_{\mathrm{c}}=\frac{2 \times 144}{100}=2.88 \mathrm{~V}$

$C=\frac{320 \times 0.45(1-0.45)}{8 \times 1.26 \times 10^{-3} \times 2.88 \times\left(50 \times 10^{3}\right)^{2}}$

$\mathrm{C}=\frac{79.2}{72576 \times 10^{3}}=1.1 \mu \mathrm{F}$

The above analysis describes nothing about the devices ideality and its control circuit. The switching losses are to be considered while selecting or designing the circuit components and ratings.

\section{Small signal analysis of buck converter}

$\left[\begin{array}{c}L \frac{d i_{l}(t)}{d t} \\ c \frac{d V(t)}{d t}\end{array}\right]=\left[\begin{array}{cc}(-R) & 0 \\ 0 & -\frac{1}{R}\end{array}\right]\left[\begin{array}{l}i_{l}(t) \\ V(t)\end{array}\right]+\left[\begin{array}{ll}1 & 0 \\ 0 & 0\end{array}\right]\left[\begin{array}{c}V_{g}(t) \\ 0\end{array}\right]$

$Y=\left[\begin{array}{ll}1 & 0\end{array}\right]\left[\begin{array}{l}i_{l}(t) \\ V(t)\end{array}\right]$

$\left[\begin{array}{l}L \frac{d i_{l}(t)}{d t} \\ C \frac{d V(t)}{d t}\end{array}\right]=\left[\begin{array}{cc}-R & -1 \\ 1 & -\frac{1}{R}\end{array}\right]\left[\begin{array}{l}i_{l}(t) \\ V(t)\end{array}\right]+\left[\begin{array}{cc}1 & -1 \\ 0 & 0\end{array}\right]\left[\begin{array}{c}V_{g}(t) \\ 0\end{array}\right]$

$Y=\left[\begin{array}{ll}1 & 0\end{array}\right]\left[\begin{array}{l}i_{l}(t) \\ V(t)\end{array}\right]$

$A=A 1 * D+A 2 * D^{\prime}$

$B=B 1 * D+B 2 * D^{\prime}$

$C=C 1 * D+C 2 * D^{\prime}$

Where

$D^{\prime}=(1-D)$

$A=\left[\begin{array}{cc}-(R) & -D^{\prime} \\ D^{\prime} & -\frac{1}{R}\end{array}\right] ; B=\left[\begin{array}{cc}1 & -D^{\prime} \\ 0 & 0\end{array}\right] ; C=\left[\begin{array}{ll}1 & 0\end{array}\right]$

$\left[\begin{array}{c}\mathrm{L} \frac{\mathrm{di}_{1}(\mathrm{t})}{\mathrm{dt}} \\ \mathrm{c} \frac{\mathrm{dv}(\mathrm{t})}{\mathrm{dt}}\end{array}\right]=\left[\begin{array}{cc}(-\mathrm{R}) & -\mathrm{D}^{\prime} \\ \mathrm{D}^{\prime} & -\frac{1}{\mathrm{R}}\end{array}\right]\left[\begin{array}{l}\mathrm{i}_{1}(\mathrm{t}) \\ \mathrm{V}(\mathrm{t})\end{array}\right]+\left[\begin{array}{cc}1 & -\mathrm{D}^{\prime} \\ 0 & 0\end{array}\right]\left[\begin{array}{c}\mathrm{V}_{\mathrm{g}}(\mathrm{t}) \\ 0\end{array}\right]$

$Y=\left[\begin{array}{ll}1 & 0\end{array}\right]\left[\begin{array}{l}\mathrm{i}_{1}(\mathrm{t}) \\ V(\mathrm{t})\end{array}\right] \mathrm{y}=\left[\begin{array}{ll}1 & 0\end{array}\right]\left[\begin{array}{l}\mathrm{i}_{\mathrm{l}}(\mathrm{t}) \\ \mathrm{V}(\mathrm{t})\end{array}\right]$

$\widehat{X}=A \hat{x}+B \hat{u}+\left\{\left(A_{1}-A_{2}\right) X+\left(B_{1}-B_{2}\right) U\right\} \hat{d}$

$A_{1}-A_{2}=\left[\begin{array}{cc}0 & 1 \\ -1 & 0\end{array}\right]$

$\mathrm{B}_{1}-\mathrm{B}_{2}=\left[\begin{array}{ll}0 & 1 \\ 0 & 0\end{array}\right]$

Linearized to standard form
$G_{v_{d}}(s)=G_{d_{0}} \frac{\left(1-\frac{s}{\omega_{2}}\right)}{\left[1+\frac{s}{Q \omega_{0}}+\left(\frac{s}{\omega_{0}}\right)^{2}\right]}$

$=\frac{\mathrm{V}_{0}}{\mathrm{D}^{\prime}} \times \frac{\left[1-\left(\frac{\mathrm{S}}{\mathrm{D}^{\prime} \mathrm{R}}\right)\right]}{1+\left[\frac{\mathrm{S}}{\mathrm{D} \cdot \mathrm{L}}\right]+\left[\frac{1}{\left(\mathrm{D}^{\prime} \mathrm{R} \sqrt{\mathrm{C} / \mathrm{L}}\right)\left(\frac{\mathrm{D}^{\prime}}{\sqrt{\mathrm{LC}}}\right)}\right]+\mathrm{S}^{2}\left[\frac{1}{\mathrm{D}^{\prime} / \sqrt{\mathrm{LC}}}\right]}$

Considering the values $\mathrm{Vin}=320 \mathrm{~V}, \mathrm{R}_{\mathrm{L}}=0.2 \Omega, \mathrm{L}=1.26 \mathrm{mH}$, $\mathrm{C}=1.1 \mu \mathrm{F}, \mathrm{R}_{0}=25 \Omega$

With the above values, the transfer function was calculated and the Bode plot was obtained as:

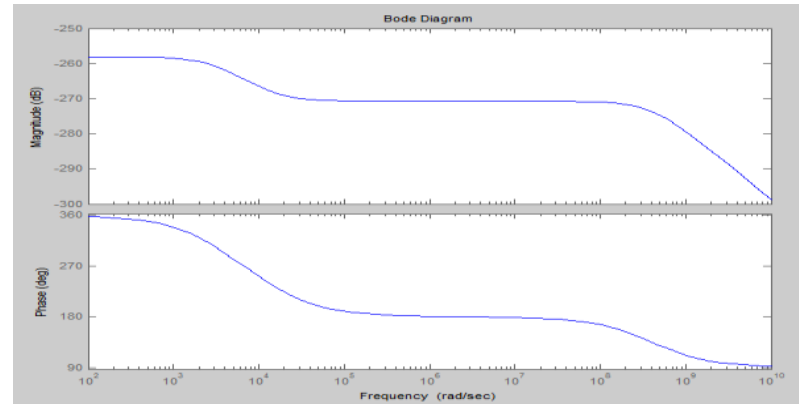

\section{V. simulation model and results}

Table 1: System Parameters

\begin{tabular}{ll}
\hline Parameter & Value \\
\hline Input Voltage (Vin) & $320 \mathrm{~V}$ \\
Output Voltage (V0) & $150 \mathrm{~V}$ \\
Inductor (L) & $1.26 \mathrm{mH}$ \\
Capacitor (C) & $1.1 \mu \mathrm{F}$ \\
\hline
\end{tabular}

Case - 1: Open loop Buck Converter.

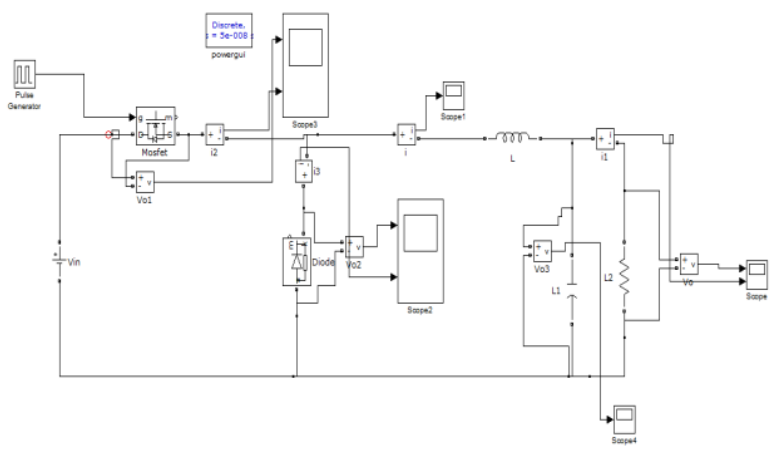

Fig. 4: Simulink Model of Open Loop Buck Converter.

Figure 4 shows the simulink model of open loop Buck converter. Here the model is simulated with $320 \mathrm{~V}$ input voltage and the output voltage is observed. The simulink model was done according to the system parameters given in Table 1.
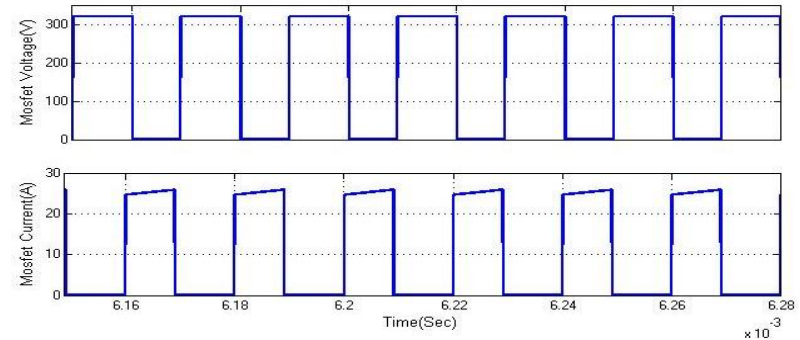

Fig. 5: Simulink Result of Voltage across Switch and Current through the Switch. 

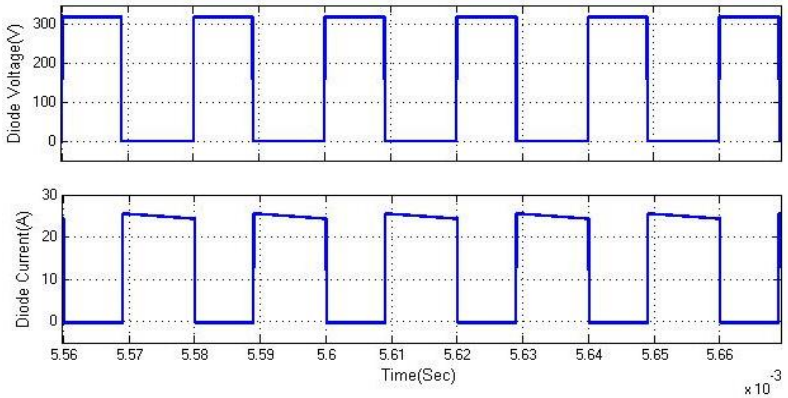

Fig. 6: Simulink Result of Voltage across Diode and Current through the Diode.

Figure 5 shows the simulink result of voltage across the main switch and the current passing through the main switch. The voltage across diode and the current through the diode are shown in figure 6. We can observe when the main switch is in ON state, the voltage across main switch is observed to be $320 \mathrm{~V}$.

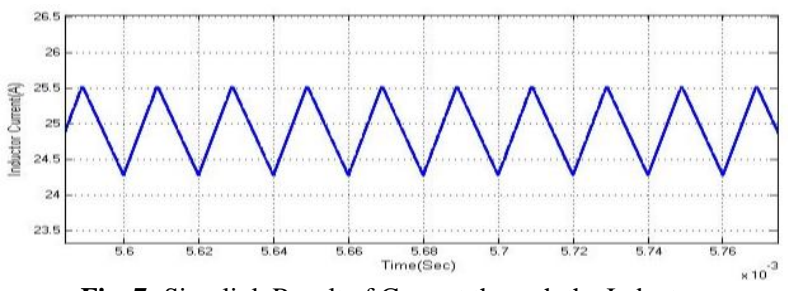

Fig. 7: Simulink Result of Current through the Inductor.

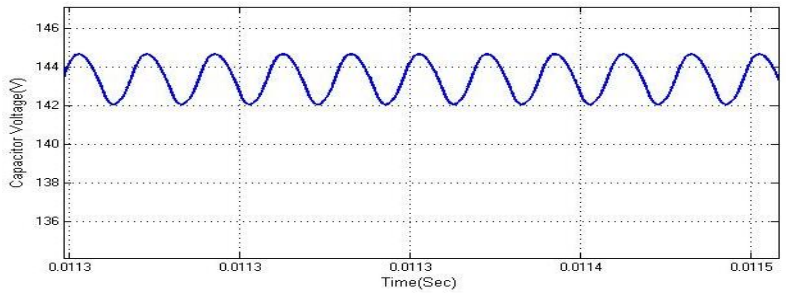

Fig. 8: Simulink Result of Voltage across Capacitor.

Figure 7 shows the simulink result of the current passing through inductor. The voltage across the capacitor was shown in figure 8 .
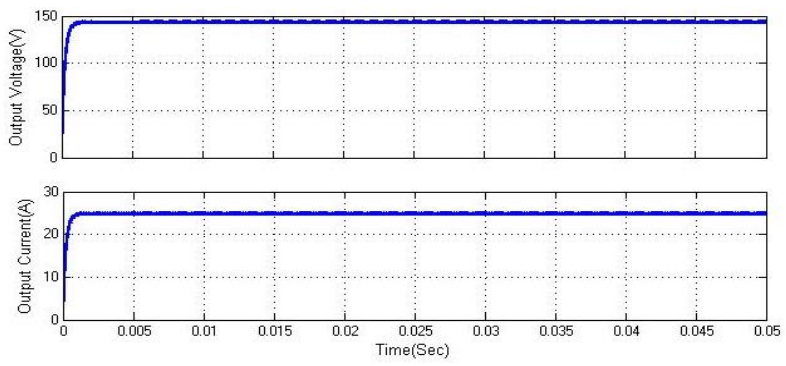

Fig. 9: Simulink Result of Output Voltage and Output Current.

Figure 9 shows the simulink result of output voltage and the output current. Buck converter is used to decrease the output voltage. From the output voltage result shows that the input voltage of $320 \mathrm{~V}$ is been decreased to $150 \mathrm{~V}$ and the output current is maintained constant with continuous conduction.

Case - 2: Open loop Synchronous Buck Converter

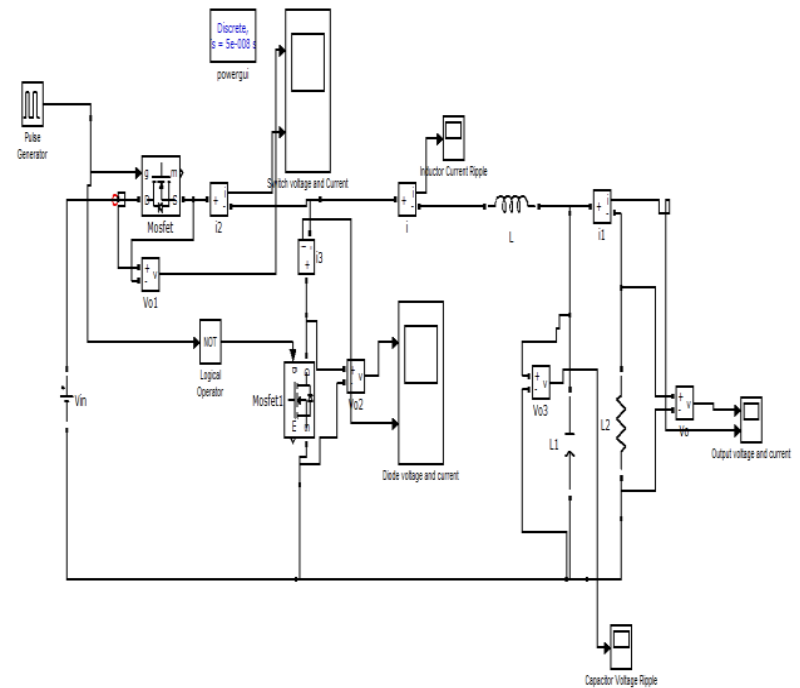

Fig. 10: Simulink Model of Open Loop Synchronous Buck Converter.

Figure 10 shows the simulink model of open loop synchronous Buck converter. Here the model is simulated with $320 \mathrm{~V}$ input voltage and the output voltage is observed. The simulink model was done according to the system parameters given in Table 1. In this model, the diode in normal Buck converter is replaced with a MOSFET

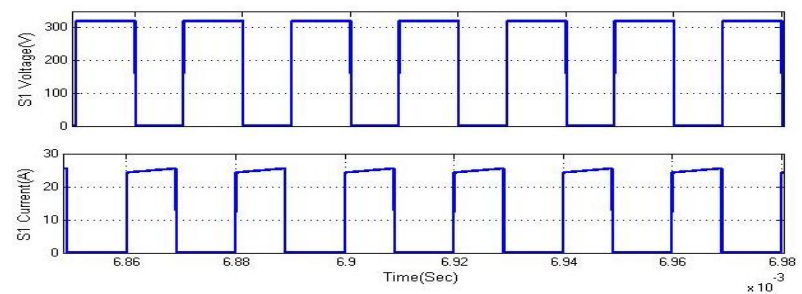

Fig. 11: Simulink Result of Voltage across Switch and Current through the Switch.
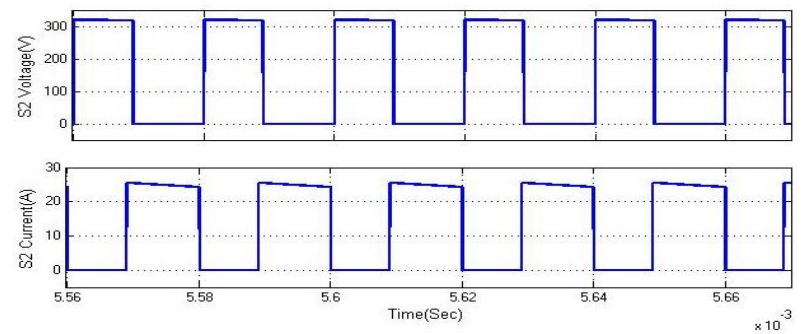

Fig. 12: Simulink Result of Voltage across Diode and Current through the Diode.

Figure 11 shows the simulink result of voltage across the main switch and the current passing through the main switch. The voltage across switch S2 and the current through the switch S2 are shown in figure 12. We can observe when the main switch is in ON state, the voltage across main switch is observed to be $320 \mathrm{~V}$.

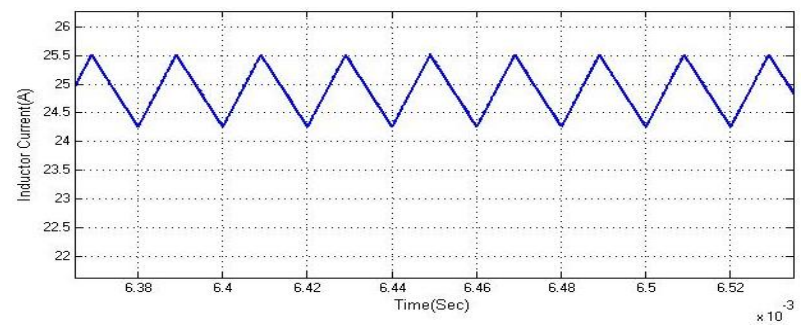

Fig. 13: Simulink Result of Current through the Inductor. 


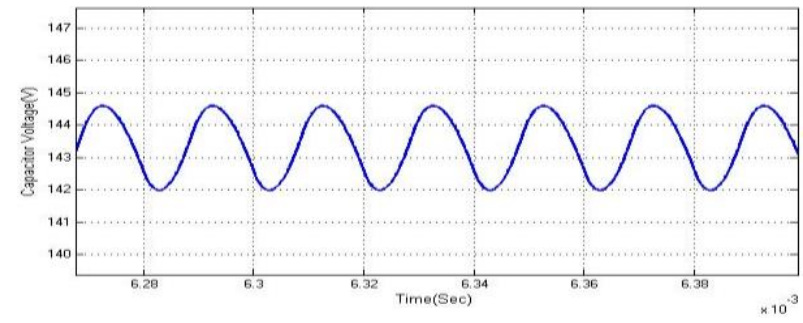

Fig. 14: Simulink Result of Voltage across Capacitor.
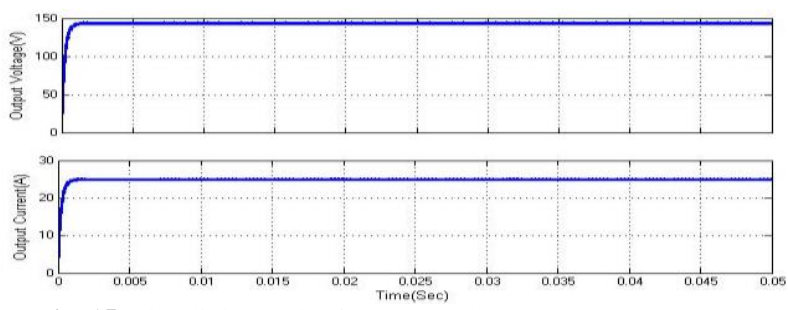

Fig. 15: Simulink Result of Output Voltage and Output Current.

Figure 13 shows the simulink result of the current passing through inductor. The voltage across the capacitor was shown in figure 14 . Figure 15 shows the simulink result of output voltage and the output current. Synchronous Buck converter is used to decrease the output voltage. The output voltage result shows that the input voltage of $320 \mathrm{~V}$ is been decreased to $150 \mathrm{~V}$ and the output current is maintained constant with continuous conduction in open loop synchronous buck converter.

Case - 3: Closed loop Buck Converter.

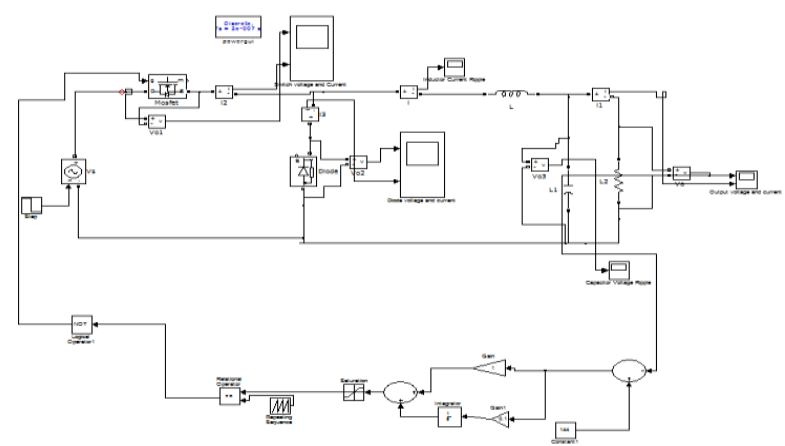

Fig. 16: Simulink Model of Closed Loop Synchronous Buck Converter.
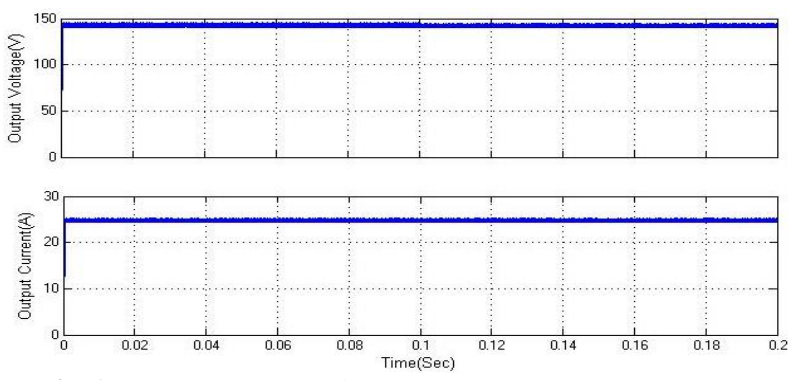

Fig. 17: Simulink Result of Output Voltage and Output Current.

Figure 16 shows the simulink model of closed loop synchronous buck converter. Figure 17 shows the simulink result of output voltage and the output current. From the output voltage result shows that the input voltage of $320 \mathrm{~V}$ is been decreased to $150 \mathrm{~V}$ and the output current is maintained constant with continuous conduction in closed loop synchronous buck converter. Closed loop operation brings the output of the converter in much less time when compared to the open loop operation which can be confirmed from the above result.

Case - 4: Closed loop Synchronous Buck Converter.

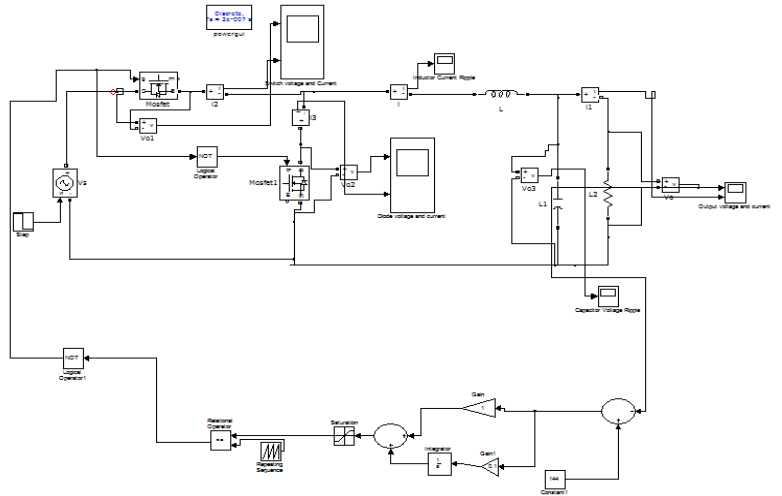

Fig. 18: Simulink Model of Closed Loop Buck Converter.
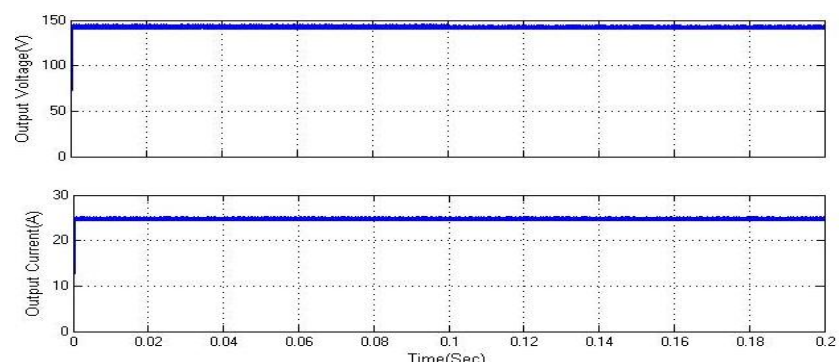

Fig. 19: Simulink Result of Output Voltage and Output Current.

Figure 18 shows the simulink model of closed loop buck converter. Figure 19 shows the simulink result of output voltage and the output current. From the output voltage result shows that the input voltage of $320 \mathrm{~V}$ is been decreased to $150 \mathrm{~V}$ and the output current is maintained constant with continuous conduction in closed loop buck converter. Closed loop operation brings the output of the converter in much less time when compared to the open loop operation which can be confirmed from the above result. The inductor current ripple and capacitor voltage ripple content is also maintained below $2 \%$ and $5 \%$ respectively.

\begin{tabular}{|c|c|c|c|}
\hline Parameter & $\begin{array}{l}\text { Theoretical } \\
\text { limit }\end{array}$ & $\begin{array}{l}\text { Buck Con- } \\
\text { verter }\end{array}$ & $\begin{array}{l}\text { Synchronous Buck } \\
\text { Converter }\end{array}$ \\
\hline $\begin{array}{l}\text { Inductor Current } \\
\text { Ripple }\end{array}$ & $5 \%$ & $1.3 \mathrm{~A}(5.2 \%)$ & $1.2 \mathrm{~A}(4.8 \%)$ \\
\hline $\begin{array}{l}\text { Capacitor Volt- } \\
\text { age Ripple }\end{array}$ & $2 \%$ & $3 \mathrm{~V}(2.09 \%)$ & $2.5 \mathrm{~V}(1.74 \%)$ \\
\hline
\end{tabular}

Table 2 represents the inductor current ripple and capacitor voltage ripples. The nominal values which we have considered is that the inductor current ripple should be less than $5 \%$ and the capacitor voltage ripple should be less than $2 \%$. Synchronous buck converter operates under satisfactory conditions with nominal specified ripple contents.

A prototype of the proposed buck converter is developed in the hardware. The PWM pulses are generated by using a PWM controller IC SG3525A. The values of the components in hardware used are detailed in Table 3.

\section{Conclusion}

DC-DC converters play a very vital role in many of the applications especially in the field of power supply to low power requirements. In this paper we have considered the application of charging batteries to drive UPS. Many DC-DC converters are available and out of which, Buck converter is very simple in construction and can provide required output. Buck converter steps down the voltage to desired level at the output. But due to the usage of diode in its circuit operates the converter with losses due to so called conduction losses in diode. To minimize the conduction losses, the diode is replaced with a MOSFET switch which 
has very less conduction losses when compared to diode. This reduction in losses can improve the converter efficiency by $5 \%$ or more. In this paper, the model of synchronous Buck converter was presented with its design. Normal buck converter was also discussed with its output results. Simulink model of synchronous buck converter with both open loop and closed loop operation was presented along with its results. Also model of normal buck converter with both open loop and closed loop operation was presented along with its results. The capacitor voltage ripple and inductor current ripple content is also maintained below $2 \%$ and $5 \%$ respectively. The input of $320 \mathrm{~V}$ is decreased to $150 \mathrm{~V}$ and the results pertaining to this discussion were also shown. Closed loop operation brings the output of the converter to its final value in much less time when compared to open loop operation in both buck and synchronous buck converter which can be observed from the output results. Hardware prototype of the above said converter was designed and the results pertaining to the hardware were also shown in detail.

\section{References}

[1] MOHAN. N., UNDELAND, T.M., and ROBBINS, W. P: 'Power electronics: converters, applications and design’ (Wiley, 1995, 2nd Edn.)

[2] KASSAKIAN, J. G., SCHLECHT, M. E, and VERGHESE, G. C. 'Principles of power electronics' (Addison Wesley, 1991)

[3] J.Mahdavi, A.Emadi, H.A.Toliyat, Application of State Space Averaging Method to Sliding Mode Control of PWM DC/DC Converters, IEEE Industry Applications Society October 1997.

[4] https://en.wikipedia.org/wiki/Buck_converter

[5] Synchronous Buck Converter Design Using TPS56xx Controllers in SLVP10x EVMs User's Guide, Texas Instruments, Sep 1998.

[6] Ching-Jung Tseng, Chern-Lin Chen "Novel ZVT-PWM converters with active snubbers", IEEE transaction power electronics, sep.1998, pp. 861-869.

[7] Elasser and D. A. Torrey, "Soft switching active snubbers for dc/dc converters," IEEE Trans. Power Electron., vol. 11, no. 5, pp.710 722, 1996.

[8] M.L. Martins, J.L. Russi, H. Pinheiro, H.A. Grundling, H.L. Hey, “ Unified design for ZVT PWM converters with resonant auxiliary circuit," Electric power applications, IEE proceedings, vol.151, issue 3, 8 May 2004, pp. 303-312.

[9] S. Kaewarsa, C. Prapanavarat, U. Yangyuen, "An improved zerovoltage-transition Technique in a single-phase power factor correction circuit," International conference on power system technology - Powercon 2004, Volume 1, 21-24 Nov. 2004 Page:678-683

[10] G. Hua, C. Leu, Y. Jiang, and F. Lee, "Novel zerovoltage-transition PWM converters," IEEE Trans. on Power Electronics, Vol. 9, No. 2, March 1994

[11] K. Wang, F.C. Lee, G. Hua, and D. Borojovic, "A comparative study of switching losses of IGBTs under hard-switching, zerovoltage-switching and zerocurrent-switching," IEEE PESC Conf. Rec., 1994, pp. 1196-1204

[12] C. Canesin, and I. Barbi, "Comparison of experimental losses among six different topologies for a $1.6 \mathrm{~kW}$ boost converter, using IGBT's," IEEE PESC Conf. Rec., 1995, pp. 1265-1271. 